ORIGINAL ARTICLE

\title{
Sports related maxillofacial injuries: the first maxillofacial trauma database in Switzerland
}

\author{
A K Exadaktylos, N M Eggensperger, S Eggli, K M Smolka, H Zimmermann, T lizuka
}

Br J Sports Med 2004;38:750-753. doi: 10.1136/bjsm.2003.008581

See end of article for authors' affiliations

.....................

Correspondence to:

Dr Exadaktylos,

Department of

Anaesthesiology and

Emergency Medicine,

Inselspital, University

Hospital Bern, Bern 3010,

Switzerland; aristomenis@

exadaktylos.ch

Accepted 7 October 2003
Background: With the increase in the amount of medical data handled by emergency units, advances in computerisation have become necessary. New computer technology should have a major influence on accident analysis and prevention and the quality of research in the future.

Objectives: To investigate the occurrence of sports related maxillofacial injuries using a newly installed relational database. To establish the first sports trauma database in Switzerland.

Methods: The Qualicare databank was used to prospectively review 57248 case histories of patients treated in the Department of Emergency Medicine between January 2000 and December 2002. Predefined key words were used to collect data on sports related maxillofacial injuries.

Results: A total of 750 patients with maxillofacial injuries were identified. Ninety (12\%) were sports related maxillofacial fractures. Most (27\%) were sustained during skiing and snowboarding, $22 \%$ during team sports such as soccer or ice hockey, and $21 \%$ were from cycling accidents. Sixty eight per cent of the cyclists, $50 \%$ of the ice hockey players and soccer players, and $48 \%$ of the skiers and snowboarders had isolated fractures of the midface. Fractures of the mandible were noted predominantly in contact sports. Conclusions: Computerisation of trauma and emergency units and the introduction of customised software can significantly reduce the workload of researchers and doctors. The effective use of new computer technology should have a considerable influence on research and the quality of future prospective and retrospective studies.
S ports injuries are the leading cause of unintentional injury in children and young people, peaking at $42 \%$ for those aged 15-24. Injuries sustained during athletic pursuits account for $23 \%$ of all traumas, second only to motor vehicle injuries, and are the leading cause of death in children. Among adults, the exact figures for sports related injuries are not known, as they tend to be grouped with all injuries and trauma. ${ }^{1}$ Although sports related injury patterns have been extensively reported, studies dealing exclusively with craniomaxillofacial trauma are still rare. ${ }^{1-5}$

The increasing number of sports and leisure related injuries, in combination with an increasing amount of medical data available and rising healthcare costs, prompted our emergency unit to look for ways to cooperate with major insurance companies in order to become more efficient in patient treatment, injury prevention, and data management.

To deal as efficiently as possible with our own data, we developed new emergency room software. This relational database represents a comprehensive electronic medical record, and has been used by our emergency department in collaboration with the Department of Cranio-Maxillofacial Surgery to optimise data management and research.

The study presented here, using this new technology, analysed the incidence, causes, and injury pattern of sports related maxillofacial trauma over a 36 month period in the Swiss capital Bern. We present an example of how the new software could be used in the future to develop a strategy for injury prevention. A further aim of this study was to establish the first maxillofacial trauma database in Switzerland.

\section{The hospital unit}

Using the Qualicare databank, we reviewed 57248 case histories of patients treated in the University Hospital's Department of Emergency Medicine from January 2000 to December 2002. The Inselspital's emergency unit and the
Department of Cranio-Maxillofacial Surgery are the only referral centres for severe craniofacial trauma in this region. They serve a population of about 1.5 million and provide 24 hour on call service.

\section{The patient population}

This study included only adult patients. Patients under 15 years of age were excluded because injury patterns and skull anatomy are different in younger patients. ${ }^{6}$

\section{Basic structure of the trauma database}

All cases of facial fracture seen by a maxillofacial surgeon were collected prospectively and screened using a defined list of key words. In the database, the cause of injury is divided into seven main categories: (a) road traffic accidents, such as car, motorbike, and car-pedestrian accidents; (b) work related accidents; (c) sports related accidents; (d) sudden illnesses, such as heart and epileptic attacks; (e) domestic accidents; $(f)$ violence; $(g)$ miscellaneous. Within these main categories, there are sub menus into which specific information related to the category can be fed-for example, type of vehicle under road traffic accident, occupational activity under work related accident, and type of sport, such as ice hockey, football, soccer, under sports related accidents. All other electronic files, with referral notes of a maxillofacial surgeon, were searched "by hand and courser" for missed cases. The detected case histories were reviewed on a monthly basis, and details of sex, age, cause and circumstances of the accident, and type and location of the facial fractures were collected. The detailed mechanism of the accident was also defined according to the International Classification of Diseases. Fractures were classified according to the anatomical site of injury. Tables 1-3 list the keywords for the sports related accidents. 


\begin{tabular}{|c|c|c|}
\hline Location & Number & $\%$ \\
\hline \multicolumn{3}{|c|}{ Midface and skull base $(n=110)$} \\
\hline Zygoma & 32 & 20.5 \\
\hline Orbita & 29 & 18.6 \\
\hline Nasal bone & 13 & 8.3 \\
\hline Le Fort I, II, III & 6 & 3.8 \\
\hline Maxillary sinus & 11 & 7.1 \\
\hline Upper alveolar ridge & 2 & 1.3 \\
\hline Anterior skull base & 8 & 5.1 \\
\hline Frontal sinus & 9 & 5.8 \\
\hline \multicolumn{3}{|l|}{ Mandible $(n=40)$} \\
\hline Median/paramedian & 12 & 7.7 \\
\hline Body & 6 & 3.8 \\
\hline Angle & 6 & 3.8 \\
\hline Ramus/coronoid process & 2 & 1.3 \\
\hline Collum/condyle & 13 & 8.3 \\
\hline Lower alveolar ridge & 1 & 0.6 \\
\hline Tooth & & 3.8 \\
\hline Total & 156 & 100 \\
\hline
\end{tabular}

\section{The electronic medical record as a tool for quality} control, education, and research

This new emergency room software was developed in collaboration with the Department of Orthopaedic Surgery at the University Hospital Bern, Harvard University (Boston, Massachusetts, USA), the Maurice E Müller Foundation (Bern, Switzerland), the "Arbeitsgemeinschaft für Osteosynthese" (AO) (Davos, Switzerland), and a software developing company (Qualidoc AG, Trimbach, Switzerland, www.qualidoc.ch). ${ }^{7}$

The result is practice oriented, easy to use software which works at the department level and provides a parallel service to Macintosh and Windows users in the same network.

All emergency room nurses and the doctors who have access to the program can immediately display complete patient notes and/or progress reports, either by typing in free text or using pre-defined key words, sentences, or text blocks, which are saved and analysed according to the principles of modern four dimensional databases. There is no need for extra entering of data into the database. The text is directly transferred to a search engine and semi-automatically coded. Diagnoses are also coded according to the International Classification of Diseases in the same way. All newly generated reports are continuously saved in the electronic medical record.

Work flow can be defined according to specialty (maxillofacial surgery, ENT, etc) and specific diagnosis. Diagnoses are always accessible, or pre-defined keywords can be used to search-for example, soccer and mandibular fracture. Information and results can be retrieved with a mouse click. Diagnoses or treatments can be marked in order to start an automatic Medline search or to search in a linked online textbook (general surgery, emergency medicine, maxillofacial surgery, etc). Access to clinically relevant data generally takes less than three seconds, and free text searches in diagnostic

Table 2 Associated injuries in 26 patients

\begin{tabular}{lll}
\hline Associated injuries & Number & $\%$ \\
\hline Cerebral & 16 & 39 \\
Thoracic & 8 & 19 \\
Upper extremities & 7 & 17 \\
Lower extremities & 6 & 15 \\
Spine & 4 & 10 \\
Total & 41 & 100 \\
\hline
\end{tabular}

fields or in discharge summaries take about five seconds. The electronic medical record allows instantaneous retrieval of past discharge summaries, other text documents, or the patient's laboratory results and radiographs. The acceptance among doctors and nurses is good to very good.

During the 36 month study period, 57248 patients were admitted to the emergency unit; 750 of them needed referral to the Department of Cranio-Maxillofacial Surgery. The facial injury had been caused by a sports related accident in 90 (78 men/12 women). Eighty five patients (94\%) were identified by the database, and only five $(6 \%)$ were detected by hand and courser. The mean (SD) age of the patients was 33.76 (15.64) years (range 15-88; 95\% confidence interval 30.47 to 37.06).

\section{Facial fractures}

A total of 156 maxillofacial fractures were found in the 90 patients. Table 1 shows the sites: $110(70 \%)$ were located in the central and lateral midface as well as in the skull base, and $40(26 \%)$ in the mandible. Broken teeth were recorded in six cases $(4 \%)$.

Of the 90 patients, half had single and half had combined fractures of the facial bone. Twenty seven patients (30\%) had fractures of the zygomatic bone, $18(20 \%)$ had fractures of the orbital floor, 13 (14\%) had fractures of the nasal bone, and $11(12 \%)$ had solitary fractures of the anterior wall of the maxillary sinus. Six patients (7\%) showed a Le Fort I, II, or III fracture (table 1). Mandibular fractures were found in 35 patients. Of these, median and paramedian fractures were most common, being recorded in 12 patients $(7.7 \%$ of all maxillofacial fractures, $30 \%$ of mandibular fractures) (table 1).

Twenty six patients (29\%) had a total of 41 associated injuries, other than injuries to the facial bone (table 2). Ten patients $(11 \%)$ had multiple associated injuries. Cerebral injuries such as brain contusion were the most common (16 patients).

\section{Sports related injury patterns}

Skiing and snowboarding were the most common causes of sports related accidents, accounting for $30 \%$ of all cases $(27$ patients). This was followed by soccer and ice hockey $(22 \%)$ and cycling $(21 \%)$ (table 3 ).

Overall, $68 \%$ of the cyclists, $50 \%$ of the hockey and soccer players, and $48 \%$ of the skiers and snowboarders had isolated fractures of the midface.

Fractures of the mandible were noted predominantly in contact sports (35\% of ice hockey and soccer accidents).

Table 3 Number of 90 patients with maxillofacial injuries listed by sport

\begin{tabular}{llll}
\hline Sport & No of patients $(\mathrm{m} / \mathrm{f})$ & Total & $\%$ \\
\hline Mountain climbing & $4 / 2$ & 6 & 6.7 \\
Ice hockey & $8 / 0$ & 8 & 8.9 \\
Cycling & $19 / 0$ & 19 & 21.1 \\
Soccer & $12 / 0$ & 12 & 13.3 \\
Baseball & $1 / 0$ & 1 & 1.1 \\
Roller skating & $1 / 0$ & 1 & 1.1 \\
Fighting sports & $3 / 0$ & 3 & 3.3 \\
Horse riding & $6 / 0$ & 6 & 6.7 \\
Rugby & $1 / 0$ & 1 & 1.1 \\
Skating & $2 / 0$ & 2 & 2.2 \\
Wrestling & $4 / 0$ & 4 & 4.4 \\
Skiing & $13 / 10$ & 23 & 25.6 \\
Snowboarding & $4 / 0$ & 4 & 4.4 \\
Total & $78 / 12$ & 90 & 100 \\
\hline
\end{tabular}




\section{What is already known on this topic}

Studies dealing exclusively with maxillofacial trauma associated with sport related accidents are rare. With the increasing number of sports related injuries, data surveillance is often difficult. Among adults, the exact figures for sports related injuries are not known, as they tend to be grouped with all injuries and trauma.

\section{What this study adds}

$94 \%$ of trauma cases from a three year period were identified by new medical software. Computer assisted medical records and electronic databases enable us to easily compare similarities and differences in cause and type of injury in relation to type of sport.

Forty one per cent of the patients were injured by another person, the remainder causing the accident themselves, without any contact with another person.

Sportspeople are particularly prone to injuring themselves during the course of their pursuits. Athletic injury is normally associated with the connective tissues, including ligaments, tendons, the tissues lining the joints, and the most vulnerable body part, the head. Even a low speed fall can change a life forever.

In this study, easily performed using a new generation of software which can easily handle today's increasing amounts of medical data and increasing numbers of injured patients, we found that patients with maxillofacial fractures caused by sports accidents accounted for only $0.16 \%$ of all patients treated in the emergency unit, but represented $12 \%$ of all referrals from the emergency unit to the Department of Maxillofacial Surgery. This is comparable to other European countries, where the incidence of sports related facial bone fractures seems to vary from less than $1 \%$ to about $15 \%$, depending on geographical region and the socioeconomic status of the area. ${ }^{-12}$ We found a peak in winter, when skiing, snowboarding, and ice hockey are very popular in Switzerland. As expected, the patients were predominantly male, as there is a predominance of men in high risk sports such as soccer, ice hockey, and other contact sports. ${ }^{11}{ }^{12}$

In Switzerland, all data on sports related injuries leading to physical impairment are collected by a state owned accident insurance company, SUVA (Schweizerische Unfallversicherungs-Anstalt), and there is strong interest from them in a sports accident surveillance system. ${ }^{3}{ }^{13}$ Such a system would be useful in establishing strategies for preventing sports injuries. A study by Finch and Mitchell ${ }^{13}$ showed that the method of data collection influences both the proportion of missing information and the sensitivity of the system, and a comprehensive method of injury surveillance will lead to a more complete data collection process. According to the study, methodological differences do not appear to substantially alter conclusions about general patient characteristics, but do have some influence on the accuracy with which broad injury data are identified.

Our study shows that injury surveillance activities can be successfully implemented in sports medicine clinics. Our electronic data collection method contributes to more efficient data collection by improving the accuracy of extensive data coverage.

In the sport of baseball, it is estimated that batting helmets with face guards may prevent reduce, or lessen the severity of nearly 4000 facial injuries. ${ }^{14-16}$ A study published in the Journal of the American Medical Association showed that players who used faceguards (devices made of plastic or metal that attach to baseball helmets) were $35 \%$ less likely to suffer facial injuries than non-users. Further, the US Centers for Disease Control and Prevention estimates that universal helmet use could save one life per day and prevent one head injury every four minutes. ${ }^{17}$

In addition, mouth protectors, which typically cover the upper teeth, can cushion a blow to the face, minimising the risk of broken teeth and injuries to the soft tissues of the mouth. Depending on the use and the sport, three types of mouth protectors are available to the public: stock (ready to go), boil and bite, and custom fitted. The American Academy for Sports Dentistry lists 40 sports for which it recommends the use of mouth guards. The National Youth Sports Foundation for the Prevention of Athletic Injuries in the United States estimates that, during any sports season, athletes have a $10 \%$ chance of sustaining an injury to the face or mouth. However, because of the mandatory use of mouth guards and helmets, this chance is only $0.45 \%$ for American football. We are sure that if mouth protectors had been used by the patients we treated, some of the tooth injuries reported in our study could have been prevented.

As a first practical result of our continuing investigation, we will ask SUVA and members of industry to encourage and at a later stage to mandate the use of new helmets with integrated face protectors in risky sports, especially skiing, in order to prevent facial trauma. Through nationwide advertising campaigns, the public should be informed that whether they are riding a scooter, bicycle, or motorcycle or playing baseball, a helmet should be worn.

Whatever the sport—from skateboarding to rollerblading, baseball to volleyball, karate to gymnastics, downhill skiing to bicycling-we advocate the use of mouth guards, face shields, eye shields, or any other protective gear that will allow athletes to save their faces.

Our preliminary evaluation of the sports related trauma data collected over three years at the University Hospital in Bern shows that computer assisted medical records and electronic databases make it possible to identify data on specific groups of patients from within huge quantities of medical data. Our database enabled us to easily compare similarities and differences in cause and type of injury in relation to type of sport.

To draw clear conclusions about the causes and possible prevention of sports related injuries, further analyses of a large amount of data are still necessary. Therefore, our department will continue to collect patient information in the database presented here.

We believe that the establishment of trauma data surveillance resources in other hospitals should be promoted. Computerisation of trauma and emergency units and introduction of customised software can contribute to a significant reduction in the workloads of researchers and doctors. ${ }^{13} 14$ Thus the increasing use of new computer technology should have a considerable influence on research and the quality of future prospective and retrospective studies.

\section{Authors' affiliations}

A K Exadaktylos, Department of Anaesthesiology and Emergency Unit, Inselspital, University Hospital Bern, Switzerland

N M Eggensperger, K M Smolka, T lizuka, Department of CranioMaxillofacial Surgery, Inselspital, University Hospital Bern

S Eggli, Department of Orthopedic Surgery, Inselspital, University Hospital Bern

H Zimmermann, Department of Emergency Medicine, Inselspital, University Hospital Bern

Conflict of interest: none declared 


\section{REFERENCES}

1 Haug RH, Prater J, Indresano AT. An epidemiologic survey of facial fractures and concomitant injuries. J Oral Maxillofac Surg 1990;48:926-32.

2 Cook HE, Rowe M. A retrospective study of 356 midfacial fractures occurring in 225 patients. J Oral Maxillofac Surg 1990;48:574-8.

3 Gassner R, Tuli T, Hachl O, et al. Cranio-maxillofacial trauma: a 10-year review of 9543 cases with 21067 injuries. J Craniomaxillofac Surg 2003;31:51-61.

4 Hogg NJ, Stewart TC, Armstrong JE, et al. Epidemiology of maxillofacial fractures at trauma hospitals in Ontario. J Trauma 2000:49:425-32.

5 Cerulli G, Carboni A, Mercurio A, et al. Soccer-related craniomaxillofacial injuries. J Craniofac Surg 2002;13:627-30.

6 lizuka T, Thoren $\mathrm{H}$, Annino DJ, et al. Midfacial fractures in pediatric patients. Arch Otolaryngol Head Neck Surg 1995;121:1366-9.

7 Exadaktylos AK, Eggli S, Schoenfeld H, et al. Information technology in the emergency room optimises clinical workflow and supports education and research. Journal of Information Technology in Healthcare 2003; 1:17-25

8 Eggli S, Holm J. [Implementation of a new electronic patient record in surgery.] Chirurg $2001 ; 72: 1492-500$
9 Maladiere E, Bado F, Meningaud JP, et al. Aetiology and incidence of facial fractures sustained during sports: a prospective study of 140 patients. Int J Oral Maxillofac Surg 2001;30:291-5.

10 Motamedi MH. An assessment of maxillofacial fractures: a 5-year study of 237 patients. J Oral Maxillofac Surg 2003;61:61-4.

11 Pickett W, Garner MJ, Boyce WF, et al. Gradients in risk for youth injury associated with multiple-risk behaviours: a study of 11,329 Canadian adolescents. Soc Sci Med 2002;55:1055-68.

12 Williams JM, Currie CE, Wright $P$, et al. Socioeconomic status and adolescent injuries. Soc Sci Med 1997;44:1881-91.

13 Finch CF, Mitchell DJ. A comparison of two injury surveillance systems within sports medicine clinics. J Sci Med Sport 2002;5:321-35.

14 Svanstrom L, Welander G, Ekman R, et al. Development of a Swedish bicycle helmet promotion programme: one decade of experiences. Health Promot Int 2002;17:161-9.

15 Marshall SW, Mueller FO, Kirby DP, et al. Evaluation of safety balls and faceguards for prevention of injuries in youth baseball. JAMA 2003;289:568-74.

16 Stephen W Marshall, Frederick O Mueller, Daniel P Kirby, et al. Evaluation of faceguards for prevention of injuries in baseball. JAMA 2003;289:568-74.

17 National Center for Injury Prevention and Control, Annual Report, 2002.

\section{ELECTRONIC PAGES}

\section{Online case reports}

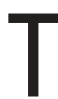
he following electronic only articles are published in conjunction with this issue of BJSM (see also pages 724,

742 , and 757).

\section{Unusual cause of wrist pain in a golfer \\ A J McHardy, H P Pollard}

Wrist injury is common in golfers and normally occurs at the impact of the club with the ball. The unusual case is reported of a low handicap golfer with wrist pain aggravated by the putting stroke. The condition was resolved with treatment. The likely mechanism for the injury is discussed.

(Br J Sports Med 2004;38:e34) http://bjsm.bmjjournals.com/ cgi/content/full/38/5/e34

\section{Half pipe snowboarding: an (un)forgettable experience or an increasing risk for head injury? G P Rajan, R Zellweger}

The case is presented of a professional half pipe snowboarder with a large post-traumatic subdural haematoma, which allowed close to normal functioning and socialisation. It is an example of a potentially life threatening sports injury in an increasingly commercialised and popular winter sport. It highlights that a knowledge of injury patterns and a high level of suspicion should be maintained in the treatment of snowboarding injuries.

(Br J Sports Med 2004;38:e35) http://bjsm.bmjjournals.com/ cgi/content/full/38/5/e35

\section{Pulmonary oedema precipitated by cold water swimming \\ R Biswas, P K Shibu, C M James}

The case is reported of a physically fit man, who, while training for a triathlon, developed pulmonary oedema secondary to swimming in cold water. Pulmonary oedema is usually caused by a combination of exercise and cold water, resulting in an increase in cardiac preload and after load, which causes an increase in pulmonary capillary pressure. Most cases improve spontaneously and quickly with no recurrence of symptoms.

(Br J Sports Med 2004;38:e36) http://bjsm.bmjjournals.com/ cgi/content/full/38/5/e36 